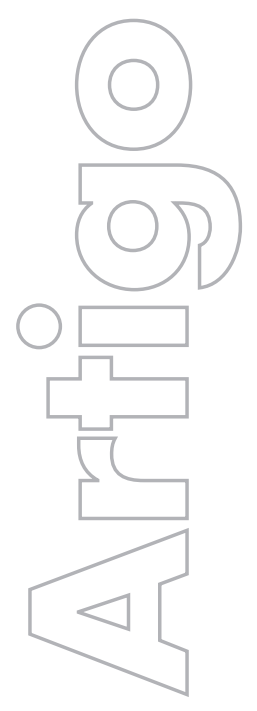

revista

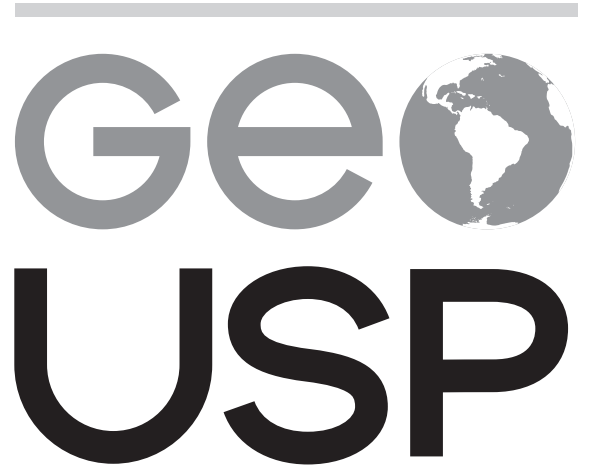

espaço e tempo

Volume 18, no 2 (2014)
A cadência de divisões do trabalho na música: o coexistir de atores sociais do circuito superior e do circuito superior marginal

\author{
Villy Creuz \\ Conicet-Universidad de Buenos Aires
}

p. $370-385$

Artigo disponível em:

http://www.revistas.usp.br/geousp/article/view/84539

Como citar este artigo:

CREUZ, V. A cadência de divisões do trabalho na música:

o coexistir de atores sociais do circuito superior e do circuito superior marginal. GEOUSP - Espaço e Tempo (Online), São Paulo, v. 18, n. 2, p. 370-385, 2014.

\section{(cc) EY}

Este artigo está licenciado sob a Creative Commons Attribution 3.0 License. 


\title{
A cadência de divisões do trabalho na música: o coexistir de atores sociais do circuito superior e do circuito superior marginal
}

\section{Resumo}

A modernização dos equipamentos de consumo e produção de músicas reorganiza o espaço geográfico e a economia das cidades. Estas acolhem a participação da música mais espraiada no tecido urbano entre diferentes grupos de atores: dos grandes e poderosos, do circuito superior, aos micro e pequenos, do circuito superior marginal. As empresas do circuito superior tendem a se reorganizar e a criar novos mercados, já as do circuito superior marginal procuram se adaptar e inventar novas maneiras de existir, com as possibilidades da técnica no período atual. A tendência oligopolista da música é reforçada ao mesmo tempo em que se expandem os meios de produção entre os atores com menos poder. Este texto busca identificar alguns pontos desse novo mercado musical do circuito superior e do circuito superior marginal da economia urbana.

Palavras-chave: Circuitos da economia urbana. Música. Cidades. Técnica. Mercado.

\section{Harmony on division of labour in music: coexistence in upper circuit and marginal upper circuit of social actors}

\begin{abstract}
Modernization of objects to customer music's and equipment's used to music's production is redrafting geography's space and urban economics at Brazilians cities. The urban tissue offer a shelter to different social actors: big companies and small business found your place at big cities. The urban system could be analyzed thought two subsystem's: the upper circuit and the lower circuit. The marginal upper circuit is where records studios and little activities related to the music
\end{abstract}


production belong. The tendency to oligopolistic status in the music is crescent. However, at the same time, small business had been your space in the urban market. This article propose to identify some points in this new dynamic of music in the urban economic system at Brazilians cities.

Keywords: Urban economic circuits. Music. Cities. Technique. Market.

\section{Introdução}

Esse texto procura revelar algumas situações geográficas (Silveira, 1999) dos atores sociais ligados, através da produção da música, a economia urbana no Brasil. Para tanto tomamos como caminho de análise os dois circuitos da economia urbana (Santos, 2002). Nessa proposta o sistema urbano é apreendido por meio de dois subsistemas: o circuito superior e o circuito inferior que, justamente, por serem partes de um mesmo sistema não são independentes, ao contrário, são complementares e estabelecem relações em diversos níveis. Existe dentro do subsistema do circuito superior uma porção marginal, em contato intermezzo, à qual M. Santos chamou de Circuito Superior Marginal (2002, p. 103). Em outras palavras, é uma porção moderna, pois está inserida na divisão do trabalho hegemônico, mas compartilha da vulnerabilidade do circuito inferior e se relaciona diretamente com ele.

A diferença de renda é a propulsora dos dois circuitos da economia, responsáveis pela estrutura econômica, mas, do mesmo modo, pelo processo de organização do espaço, com a fabricação de diferenças quantitativas e qualitativas dos tipos e regularidades do trabalho e do acesso ao consumo.

A abordagem da urbanização nacional pela via da teoria dos dois circuitos nos dá uma percepção sobre o movimento de formas de consumo diversificadas e hỉridas que convivem nas cidades. $O$ circuito superior:

Consiste nas atividades criadas em função dos progressos tecnológicos e das pessoas que se beneficiam deles. $O$ outro [circuito inferior] é igualmente um resultado da mesma modernização, mas um resultado indireto, que se dirige aos indivíduos que só se beneficiam parcialmente ou não se beneficiam dos progressos técnicos recentes e das atividades a eles ligadas (Santos, 2002, p. 29).

O que diferencia o circuito superior e o inferior são, basicamente, os graus de capitalização, tecnologia e organização dos atores sociais. Essas três variáveis constituem situações geográficas particulares, segundo também, a localização e a inserção no meio construído urbano desses grupos de atores.

Nas palavras de María Laura Silveira (2006, p. 86), estamos num mundo em situações, aliás, é a própria existência um conjunto de situações.

Estamos com as coisas, com os outros homens e numa esfera de significados. De alguma forma, estamos compartilhando valores morais, culturais, civilizatórios, que nos dão uma oportunidade de entendimento. É a cultura que nos oferece uma cosmovisão, pois vemos o mundo a partir dela. 
São situações concretas, nas quais materialidade e ação se aderem a todas as existências no espaço geográfico. Como ponderou Lucien Goldmann (1972, p. 29), os caminhos estão a refazer os desdobramentos das situações que se cristalizam em normas e modos de agir na sociedade, num caráter dialético:

Toda situação criada pelo homem tem um caráter dialético e comporta aspectos contraditórios. $\bigcirc$ problema central vem a ser o da estratégia, que permitiria tornar eficaz a ação dos que intentam servir-se das mass-media em um objetivo efetivamente criador e cultural.

A informatização do território nacional, com início na década de 1990, amplia essas possibilidades de trabalho e de produção da psicoesfera nacional. ${ }^{\prime} \bigcirc$ mercado da música está revestido da produção de símbolos culturais, no qual o circuito superior tem a primazia, já que conta com maiores e mais complexas estruturas de organização, elegendo pontos do território para a produção; e, na distribuição, sendo capaz de tocar todas as porções, além de deter os meios de direcionar os consumos através da propaganda.

O circuito superior da música apesar de toda reforma organizacional que aconteceu na década de 1990, advinda das novas técnicas de produção e consumos musicais, tende a conservar o domínio sobre o mercado e fortalecer os círculos de cooperação. Do mesmo modo, atores com menores graus de organização, tecnologia e capital, conseguem subsistir e explorar novas fronteiras da expressão e criação, mediados pela música.

\section{A hegemonia do circuito superior}

Cada divisão do trabalho supõe a existência de arranjos na produção, distribuição e consumo no território usado (Santos, 1996). Há um conflito de interesses e disputas de poder entre os diferentes atores, embora sejam, ao mesmo tempo, solidários entre eles, porque suas funções interdependem umas das outras. Todavia, o conflito não cessa, já que não prescinde da disputa pela sobrevivência no mercado dentro do sistema urbano. Uma primeira aproximação dessas leituras nas cidades, ${ }^{2}$ à luz da teoria da economia urbana, mostra que a cidade não se desenvolve sob os pilares da economia hegemônica, de grandes empresas de inovação e difusão tecnológica, mas são as micro, pequenas e médias empresas (ou atividades) as responsáveis pela ocupação da maior parcela de população economicamente ativa.

$\bigcirc$ trabalho de empresas ligadas à música redescobre grandes mercados que se valem dessa produção incessante de opiniões e discursos a se amparar na música com intuito de aproximar-se dos indivíduos (Barenboim, 2009;; Maffesoli, 2008, ${ }^{4}$ Lipovestsky, 2005). ${ }^{5}$

1 Como escreve Milton Santos (1996), a psicoesfera é esse universo de valores, símbolos e desejos. A noção de psicoesfera aproxima-se do sentido de cosmovisão e se relaciona diretamente a ideia de cultura. Mas a psicoesfera não pode ser entendida sem a noção de tecnoesfera (Santos, 1996), que são os objetos, em seu conjunto e sistemas, a permitir as ações dos atores sociais em seu respectivo momento histórico.

2 Pesquisas que apontam a manifestação desse fenômeno têm sido elaboradas e orientadas por María Laura Silveira, cuja linha de investigação trabalha com fenômenos do sistema da economia urbana em cidades brasileiras e latinoamericanas a partir da leitura dos dois circuitos.

3 Para Daniel Barenboim (2009, p. 125), "O poder da música reside em sua capacidade de se comunicar com todos os aspectos do ser humano".

4 "Dionísios pós-modernos! Rapazes e moças em transe dançam ao som de ritmos bárbaros. A música tecno domina. Pouco importa o resto" (Maffesoli, 2008, p. 15).

5 "Vivemos uma formidável explosão musical: música interminável, paradas de sucesso, a sedução pós-moderna é hi-fi. Daqui por diante, o aparelho de som é um bem de primeira necessidade, praticamos esporte, passeamos, trabalhamos com música, dirigimos em estéreo, a música e o ritmo se tornaram em poucos decênios parte permanente do nosso ambiente, trata-se de um entusiasmo de massa" (Lipovetsky, 2005, p. 6-7). 
A extensão dos objetos, ainda que descontínua, com a intermitência dos tipos e regularidades de consumo, nas diferentes camadas de população, conhece no período da globalização, o ápice da capacidade de organização da vida social. À exemplo: a telefonia móvel a catalisar o contato entre indivíduos na sociedade, redimensionando a possibilidade de comunicação entre os homens. Alargou-se a troca de experiências e culminou na aceleração do intercâmbio de relações interpessoais, de trabalho e da própria organização da divisão social e territorial do trabalho.

Não há comunicação sem um objetivo a alcançar, isto é, toda comunicação pressupõe um propósito. Jürgen Habermas (1988, p. 105) afirma que "a um nível mais geral, todas as acções, linguísticas ou não linguísticas, podem ser vistas como actividade orientada para um objectivo". $\bigcirc$ ato de comunicar comporta uma finalidade intrínseca à ação. A comunicação, ampliada pelos incrementos de técnica no território, isto é, o aparelhamento territorial, confere aos usos do espaço geográfico novos sentidos aos quais os agentes tendem a agregar valor.

A cultura, como elemento da relação biunívoca do território e da moral dos atores, dimensiona novos aconteceres e manifestações por meio de novos usos (usos que são também culturais), autorizados pelo sistema de objetos. Em certa perspectiva, o sistema de ações tende a ser, entrementes, arquitetado de modo que se estabeleça a harmonia de uma constante recriação da configuração territorial.

A internet é um vetor que redimensionou toda a divisão do trabalho entre as firmas ligadas à música. A presença da internet, entre grupos de famílias de até dez salários, abre a possibilidade da chamada pirataria musical. A pirataria se tornou, ao revés, a expressão da força e do intuito de controle dos atores do circuito superior em produzir contra discursos. ${ }^{6}$ Mesmo que não se queira ou possa pagar pela música, há um esforço por parte da sociedade em consumir o discurso (musicados) feito pelas grandes empresas.

Ainda que os consumos se tornem possíveis, mediante a compra não regulada pelo Estado, a produção de demandas e por gostos musicais continua atrelada ao desempenho dessas firmas. Se uma cantora como Ivete Sangalo (à guisa de exemplo e sem juízo de valor) chega a ser uma referência internacional da produção cultural brasileira é porque houve a divisão intelectual do trabalho, vinculando marketing à logística de distribuição: cria-se um nome como marca.

A pirataria retira das empresas uma considerável porção de suas receitas, mas não recua quanto à capacidade de produção de iconografias - retomando a expressão de Gottmann (1952), que então, aqui, chamaríamos de iconografias musicais.

A força da produção de discursos dos agentes do circuito superior serviu para transitar entre o período predecessor ao presente, com a ruptura que as novas tecnologias trouxeram à forma de consumir produtos culturais. $O$ sistema de técnicas (aumento da informática no Brasil) autorizará novos usos, concomitante ao fato de que também conduzirá a novos cerceamentos.

Quando microcomputadores se espalham no território nacional há um novo vetor de arranjo da produção, distribuição e consumo nas cidades. Justamente porque é a cidade "meio de produção material e imaterial, lugar de consumo, nó de circulação" (Santos, 1994, p. 118). A socialização possibilita, de tal modo, "a inserção na economia urbana de um número crescente de pessoas" (Santos, 1994, p. 120).

6 Em sua tese de doutorado, Fabio Tozi propõe entender o fenômeno da chamada pirataria: "a pirataria é geograficamente reveladora das disputas existentes entre distintos projetos sociais de uso do território" (2012, p. 25). 


\section{As tecnologias musicais no período da globalização: novos semoventes}

Denominaremos semoventes musicais objetos portáteis que permitem deslocamentos com músicas. Tecnologias como tocadores de MP3, rádios portáteis, celulares e outros dispositivos que aportam ao consumo musical (junto ao corpo) são exemplos de semoventes musicais. A miniaturização dos objetos autoriza movimento de informações, esse mover próprio do objeto. A telefonia celular, em especial, converte-se num instrumento de difusão musical, já que os aparelhos abrangem a função de rádio AM e FM e reprodutor de arquivos MP3.

O consumo toca a todos e em todos os ramos de firma, bem como em todo corpo social. Dentre a variedade de consumos, a música se desvela como objeto de grande procura, mediada pelos novos objetos que compõem o sistema de técnicas, entre eles os semoventes musicais que ampliam essa capacidade de alcance da música nos lugares e no cotidiano da sociedade.

Geralmente, os tocadores de músicas operam com arquivos comprimidos de MP3 baixados da rede de computadores. Esses aparelhos surgem como uma demanda posterior ao compartilhamento de canções na internet, mas uma vez que haviam sido lançados, abriram uma enorme fonte de demandas musicais na web.

Novos tipos que equipamentos tornam-se também semoventes musicais, como os tablets que são computadores em forma de pranchetas. São leves, com alta capacidade performática, com acesso à internet e diversos softwares. Esses equipamentos permitem baixar músicas da rede e escutá-las com fones auriculares. Convertem-se em novas ferramentas de trabalho e, dentre as funções possíveis, a reprodução de músicas está incorporada. Michael Bull (2007, p. 21) pondera:

Através do poder do som o mundo torna-se íntimo. A tecnologia dá poderes aos ouvidos [...]. Esta capacitação está incorporada aos fones de ouvido que suplanta o ruído incontrolável e caótico da rua com sons fechados de consumidores individuais. $\bigcirc$ preço da mediação tecnológica é a privatização.

Se, por um lado, os semoventes potencializam a privatização dos sentidos nos indivíduos, uma vez que a sonoridade está encerrada nos fones auriculares e o indivíduo, nessa dinâmica, tende a tornar-se mais privatista e isolado, por outro, há ao mesmo tempo, o aumento da demanda e das trocas musicais que recusam a reclusão. De fato, os sujeitos tendem ao individualismo, embora sejam, concomitantemente, mais cosmopolitas, já que a unicidade técnica denota conhecer outros (o novo sempre reciclado), sobretudo o saber do outro, seus gostos e vocações culturais, em uma troca permanente. É um arranjo da dialética que, transpassado pelo isolamento, alcança o intercâmbio.

\section{Novos atores no circuito espacial de produção da música}

A nova estrutura organizacional de produção musical no país inseriu novos atores na divisão do trabalho nas cidades. De modo que serviços ligados à computação e à programação tornam-se etapas do circuito espacial de produção.

A empresa Apple, em seu site, oferece download gratuito de um software chamado iTunes. $\bigcirc$ iTunes Store é um site dentro do programa que executa as músicas no formato específico da Apple. Portanto, se meu intuito é comprar uma música dessa empresa é necessário 
que trabalhe com a ferramenta dessa empresa. Esse programa é pressuposto para indivíduos, usuários dos semoventes da Apple, como o iPod, Ipad (tablet), iPhone (celular) e os computadores. Através desse programa é possível comprar músicas.

Com o programa iTunes Match as músicas adquiridas podem ser guardadas em servidores da empresa Apple, uma espécie de nuvem digital. Cada sujeito tem uma biblioteca para armazenar os arquivos musicais comprados, que podem ser copiadas em, no máximo, cinco aparelhos. Essa firma elaborou um sistema de técnicas que não permite o compartilhamento de músicas indefinidamente. Se, por exemplo, somos donos de um iPod, não estamos autorizados a usar o dispositivo e repassar os arquivos de MP3 a outros aparelhos ou a outros computadores. A chamada "sincronização" apenas acontece de um computador, com o programa iTunes, a um desses semoventes musicais da Apple. A rigidez do sistema técnico ordenado por essa firma é muito maior do que nas demais.

A loja digital da Apple, criada em 2003 nos EUA, destaca-se nesse novo período de reorganização das empresas fonográficas nacionais e internacionais. Essa empresa destacou-se por lançar as variáveis-força. ${ }^{7}$

As empresas de tocadores de MP3, computadores, softwares, telefones celulares, empresas de telefonia móvel (Vivo, Claro, Oi e TIM), grandes cadeias de lojas de discos (Livraria Cultura, Livraria da Vila etc.), mais os portais da internet (Terra e UOL) estão todos muito bem entrelaçados às empresas do circuito superior musical, como os grupos Sony Music e Universal, entre outras.

Há uma verdadeira parceria entre essas empresas, uma concentração da força de comando e da lógica da produção da mais-valia globalizada. Richard Sennett (2006b, p. 63) afirma que esse parece ser um fenômeno cujos eventos se excluem, mas que todavia se afirmam no paradoxal da situação: "As mudanças nas redes, mercados e produção que ele utiliza permitem o que parece ser um oximoro, a concentração de poder sem centralização de poder". $\bigcirc$ poder difuso é uma forma de exercer poder, ainda que esteja descentralizado por uma série de etapas e processos produtivos; há um nicho de comando na organização das empresas dispersas em pontos do território.

A comercialização da música digital, possível graças à tendência universal da técnica, fomenta a expansão da economia entre agentes responsáveis por veicular informações. Isto é, mais um grupo de atores na economia urbana passa a integrar as etapas produtivas da música: é o caso da UOL MegaStore, divisão interna ao servidor da UOL (portal da internet largamente difundido no Brasil), na qual o indivíduo precisa (norma) se cadastrar para comprar créditos, que variam de $R \$ 5,00$ a $R \$ 120,00$. As músicas são comercializadas a partir de $R \$ 0,30$. Caso seja proprietário de um dispositivo da Apple terá de gravar esses arquivos num disco e transferir ao iTunes, no formato de CD, a partir de músicas gravadas. As empresas ligadas à informação (como veículos) são a ponta da cadeia produtiva e da disseminação de ideias, discursos e produtos (a música, à guisa de exemplo).

7 Variáveis-força são vetores de reestruturação de um conjunto de atividades. Geralmente, estão relacionadas às tecnologias e são produzidas por agentes do circuito superior, capazes de investir em inovação. 
Outro caso de músicas comercializadas por atores vinculados à informação é o Terra Sonora (divisão do portal Terra), no qual as músicas permanecem disponíveis durante o intervalo da assinatura, cujos preços mensais vão de $R \$ 19,90$ a $R \$ 59,90$ e os downloads podem ser feitos a partir de computadores e celulares.

As operadoras de telefonia celular têm suas próprias lojas virtuais. Os indivíduos baixam as músicas diretamente no computador ou do celular. Uma faixa como "Just dance" de uma cantora globalizada como Lady Gaga pode ser baixada por $\mathrm{R} \$ 4,99$ na Operadora Claro, por $R \$ 4,30$ na Vivo, e por $R \$ 3,99$ na Tim.

A nova institucionalização das firmas do circuito superior, dentro da própria hierarquia de funções e atribuições, ou seja, terceirização e ampliação do mercado pela digitalização, permite a manutenção de suas respectivas atividades, onde a manutenção e a busca pela ampliação da mais-valia tornam-se possíveis. Nas palavras de Sennett (2006a, p. 52) "numa organização flexível, o poder fica concentrado no centro; a unidade central de processamento da instituição estabelece as tarefas, avalia os resultados, promove a expansão ou o encolhimento da empresa". Nesse sentido, falar em crise da indústria fonográfica é uma falácia, uma vez que a estrutura de comando e os agentes envolvidos nas etapas de produção diversificaram suas funções e expandiram seus negócios.

Não houve alteração entre aqueles que são a ponta da hierarquia. Houve, isso sim, uma reestruturação da organização entre esses agentes, sem o desmantelamento das atividades produtivas em si, terceirizando-as frente às modernizações no território, fomentando novos tipos de consumo entre as diferentes camadas de população.

No livro Organizações modernas, ao tratar das formas de consumo e concepção da organização das empresas, Amitai Etzioni (1967, p. 148) escreve:

O papel do freguês [...] dividiu-se em dois: consumo, no sentido em que recebe serviços e bens para a satisfação de suas necessidades, e controle da distribuição dos recursos segundo suas necessidades. Embora o consumo tenha sido mantido pelo consumidor [...], até certo ponto o controle foi tirado dele e aplicado em outros papéis.

Nesse sentido, vistos e tomados por si próprios e pelos agentes de mercado como consumidores, os indivíduos são objetos de estratagemas baseados em lógicas comerciais, resultando numa associação perversa, na qual a cultura passa a ser pensada sob as lentes da lei da oferta e da procura.

María Laura Silveira (2009, p. 16) pondera:

O anverso da medalha é um conjunto difuso de totalitarismos exercidos pelas grandes empresas, que se relacionam com descumprimento de serviços, prazos, tarifas, contratos, invasão da privacidade, entre outros. Fundados em tecnologias modernas e em técnicas de ação, esses totalitarismos tornam-se hoje condição sine qua non para garantir a concorrência entre parceiros-rivais. É uma guerra sem quartel. 
A técnica cristalizada através de uma política deriva numa organização do uso territorial em que as ações de instituições, indivíduos e empresas introjetam a racionalidade dos objetos técnicos na práxis do espaço geográfico. Isso é corrente quando tratamos da prática dos semoventes musicais no cotidiano da sociedade. É a face da técnica, na qual a "informação permite a ação coordenada" (Santos, 1996, p. 178). É o projeto de construção de uma sociedade desenhado por um punhado de agentes com o controle da ação e da capacidade de influência sobre a realização do consumo e da produção da vida.

Para Jacques Ellul (1968, p. 84), os homens do nosso tempo consideram o automatismo justo e bom. $\bigcirc$ autor considera o primeiro aspecto do automatismo como a escolha entre os métodos, o maquinismo, as organizações, as fórmulas padronizadas de ações que tendem a se efetuar automaticamente. $\bigcirc$ homem é privado de sua escolha e está satisfeito com isso. Aceita, dando razão à técnica.

Tornada uma forma de satisfação imediata de desejos, a música tende a ser mais corruptora do que libertadora como fórmula empregada pelos agentes do circuito superior. Tornada mercadoria, há lógicas e técnicas administrativas que orientam sua produção. $\bigcirc$ pior risco: é uma mercadoria com capacidade de entrar em contato com a alma dos homens. Daí o risco de ser transformada em um mecanismo de alienação.

Diríamos, com M. Santos (1992, p. 64), que:

A cultura de massa, denominada cultura por hegemônica, é frequentemente, um emoliente da consciência. $\bigcirc$ momento da consciência aparece quando os indivíduos e os grupos se desfazem de um sistema de costumes, reconhecendo-os como um jogo ou uma limitação.

De modo que, nessa dinâmica, as novas formas de organizar a estrutura produtiva de mercadorias musicais tratam diretamente da maneira pela qual os homens se relacionam com seu entorno.

\section{Manifestações das topologias do circuito superior}

Como temos sustentado, as empresas ligadas à cultura, no lato sensu, a música em especial, reconhecem uma nova hierarquia de funções de suas firmas. Segundo Ana Clara Torres Ribeiro (1997, p. 156-157), "As novas formas de administração de mercados estabeleceram as bases para a afirmação de profundas mudanças culturais". A apropriação dos símbolos se relaciona à repartição de tarefas e do uso do território pelos objetos. De sorte que "Os objetos que formam o meio não são, apenas, objetos culturais; eles são culturais e técnicos, ao mesmo tempo" (Santos, 1996, p. 188).

A divisão social e territorial do trabalho mediada pela técnica depende de decisões políticas que se relacionam diretamente às decisões econômicas, via produção de normas do Estado a garantir sua manutenção. Daí a ideia de que o sistema urbano é a própria economia.

$\bigcirc$ grande conflito entre empresas do circuito superior com a venda de produtos não tributados ao Estado engendra a produção de normas, como a Lei de Direitos Autorais, n. 9.610/1998. É o esforço por parte do aparelho do Estado em regular a economia política do território atuando sobre os agentes que comercializam fora das diretrizes dos regimentos legais e que afetam o lucro de grandes empresas. 
Dentro das etapas mais amplas de confecção de um disco, entre empresas do circuito superior, há a (i) pré-produção, (ii) produção, (iii) distribuição e comercialização e, por último, (iv) consumo. Trataremos, aqui, apenas sobre a pré-produção e a produção.

Na pré-produção (i), estão envolvidas etapas desde o ensino de música aos artistas, educação musical, formação de técnicos de som, formação de executivos para processos de produção industrial ou para gerir empreendimentos de organização de eventos e espetáculos, formação de públicos através do ensino musical, o que supõe garantir, uma melhor qualidade musical ajustada ao conhecimento técnico e cultural do público (Sebrae, 2005). A etapa de pré-produção envolve a indústria de instrumentos musicais, a indústria de equipamentos de som e gravação, bem como as empresas que prestam serviço à execução dos projetos (marceneiros, pedreiros, eletricistas), escolas de ensino musical e de profissionais da música (universidades, institutos, conservatórios) e a própria financeirização das atividades voltadas aos empréstimos às pessoas físicas e jurídicas. No que tange à produção (ii) em si ressaltamos que uma vez estabelecido o que será gravado, ou seja, já completados os arranjos, composições e o repertório, passa-se então à gravação em estúdio, na qual as etapas de gravação, mixagem, masterização serão somadas à produção fonográfica e audiovisual. Na sequência entram a produção gráfica (desenho da capa), o design e o texto (do álbum) e, finalmente, a impressão. Paralelamente às fases de gravação são obtidas licenças junto aos autores, junto com certificações do Escritório Central de Arrecadação e Distribuição (Ecad). Igualmente entram as atividades ligadas à fabricação, a partir do suporte matriz. A produção dos suportes virgens pode ser feita por terceiros ou pelas próprias gravadoras. Constatamos que a maior parte das empresas tende a terceirizar os serviços de fabricação. Dentro dessa divisão territorial do trabalho das empresas de queima de discos há uma concentração desses tipos de empresas na Zona Franca de Manaus, no estado do Amazonas, região Norte do país.

A distribuição e a divulgação também são as etapas em que entram as variáveis chaves do período, uma vez que o domínio da informação e da organização das empresas permite a distribuição geográfica dos discos, bem como sua difusão.

Entre as empresas do circuito superior, as majors, a divulgação acontece por meio de campanhas de marketing, peças publicitárias, listas de execução em grandes rádios do país, negociações com canais de televisão para programas ao vivo, bem como suporte técnico e financeiro à realização de turnês nacionais ou internacionais.

A respeito deste último ponto frisamos que, por meio de entrevistas abertas aos artistas em São Paulo, verificou-se que os shows são a grande fonte de renda na atual organização do trabalho através da música. Por essa razão, as firmas do circuito superior têm buscado um controle mais rígido dos contratos com artistas, garantindo uma maior participação na produção e nos lucros decorrentes das turnês. Essa tem sido a maneira com a qual essas empresas tornaram-se gestoras das carreiras individuais de músicos e cantores, isto é, controlando todas as etapas de produção, inclusive as apresentações.

Algumas formas de consumo podem engendrar meios de comercialização. Embora no consumo haja outro ponto importante que agrega custo na soma total do disco, a contribuição do Imposto sobre Circulação de Mercadorias e Prestação de Serviços (ICMS), mais o Imposto Sobre Serviço de qualquer natureza (ISS). 
○ consumo de música se realiza através do rádio, da televisão, dos aparelhos de telefonia móvel, em espetáculos (gratuitos ou pagos), pela venda de CDs e DVDs, bailes, teatros, cinemas, festivais de música, festas populares locais (festa de São João, festa do peão, festa da uva etc.), restaurantes, bares, danceterias, academias e escritórios.

Podemos ver, nas tabelas a seguir, o número de empresas de gravação de som e edição de música. $\bigcirc$ número de empresas que trabalham é bastante expressivo e corresponde a uma grande economia produzida nas cidades. Este nos parece ser o resultado do que entendemos como reflexo do aumento da demanda e da banalização técnica de tecnologias de produção e consumo musicais.

\section{Tabela 1}

Empresas de gravação de som e de edição de música - Regiões Metropolitanas - Brasil, 2009

\begin{tabular}{l|c}
\hline Região Metropolitana & empresa \\
\hline Belém & 5 \\
\hline Fortaleza & 193 \\
\hline Recife & 108 \\
\hline Salvador & 33 \\
\hline Belo Horizonte & 134 \\
\hline Rio de Janeiro & 665 \\
\hline São Paulo & 632 \\
\hline Curitiba & 65 \\
\hline Porto Alegre & 86 \\
\hline total (outras Regiões Metropolitanas inclusas) & 4.712 \\
\hline
\end{tabular}

fonte: Elaboração própria, com base na Rais (2009).

Onúmero de empresas que trabalham com música é bastante expressivo no Brasil, sobretudo nas Regiões Metropolitanas (RM). Ainda que haja uma considerável concentração de força e poder de alguns atores, há, doravante, outra grande parcela de agentes que se valem da terceirização de serviços antes realizados nas grandes gravadoras, como gravação em estúdio, mixagem a masterização, bem como as etapas de prensagem do disco e distribuição. Todas essas fases do processo produtivo tendem a ser, no atual período, descentralizadas. 


\section{Tabela 2}

Atividades de gravação de som e de edição de música - Brasil - capitais - 2009

\begin{tabular}{l|c|l|c}
\hline capital estadual & número de firmas & capital estadual & número de firmas \\
\hline Porto Velho & 47 & Aracaju & 0 \\
\hline Rio Branco & 11 & Salvador & 32 \\
\hline Manaus & 150 & Belo Horizonte & 129 \\
\hline Boa Vista & 15 & Vitória & 30 \\
\hline Belém & 5 & Rio de Janeiro & 650 \\
\hline Macapá & 0 & São Paulo & 538 \\
\hline Palmas & 17 & Curitiba & 62 \\
\hline São Luís & 45 & Florianópolis & 139 \\
\hline Teresina & 2 & Porto Alegre & 82 \\
\hline Fortaleza & 190 & Campo Grande & 60 \\
\hline Natal & 13 & Cuiabá & 89 \\
\hline João Pessoa & 105 & Goiânia & 56 \\
\hline Recife & 15 & total & 4.712 \\
\hline Maceió & & & 12 \\
\hline
\end{tabular}

fonte: Elaboração própria, com base na Rais (2009).

As tabelas permitem observar a primazia de São Paulo-SP e do Rio de Janeiro-RJ como metrópoles com maior concentração de empresas ligadas à produção musical. De um lado, há um número relevante de artistas nessas cidades. De outro, há um número maior de empresas que demandam mais serviços na divisão de tarefas tornadas mais complexas. Devemos considerar também que a procura por esse tipo de presteza é maior em cidades com um alto de número de igrejas ${ }^{8}$, escolas de música, centros culturais e casas de show, por criarem uma massa de pessoas aptas a produzir música.

As cidades de Manaus-AM, Recife-PE, Fortaleza-CE, Belo Horizonte-MG e Florianópolis-SC igualmente concentram um número expressivo de empresas de gravação de som e edição de música.

Pelos dados das Tabelas 1 e 2, percebemos que as capitais têm a maior concentração de empresas nas respectivas RM. Em Recife, 105 empresas de gravação de som e edição estão na capital, enquanto a RM tem apenas 108. O mesmo acontece com outras cidades: há 129 empresas na cidade de Belo Horizonte, enquanto sua RM soma 134, isto é, apenas cinco a mais; em Porto Alegre, há 82 empresas na capital e 89 na RM; em Fortaleza, 190 na capital e 193 na RM.

8 Nos trabalhos de campo entre 2009 e 2012, constatou-se que as igrejas têm um papel relevante no ensino musical. 
A concentração evidencia fatores de localização (centralidades, fluxos de mercadorias e pessoas), redes de serviços técnicos e um amplo mercado consumidor. Há, certamente, a primazia de atividades nas capitais.

No caso da cidade de São Paulo, temos de relativizar esse dado, pois a capital concentra o maior número de empresas (538), enquanto a RM soma 632. Nesse caso, a concentração de pessoas e de outras atividades no $A B C$ paulista não permite que essa discrepância seja acentuada.

\section{Algumas situações do circuito superior marginal da música}

A partir do trabalho de campo nas cidades de São Paulo, Rio de Janeiro, Goiânia, Recife e Porto Alegre, gostaríamos de trazer alguns elementos da pesquisa (Creuz, 2012) relacionados ao aumento da participação de estúdios de gravação e pequenos gravadores na economia urbana a partir da banalização das técnicas (Santos, 1998) e com o uso do meio construído urbano (Harvey, 1982) diversificado entre moradia e locais de trabalho.

O barateamento dos equipamentos de trabalho (mesas de som, computadores, programas e softwares, microfones e cabos) e a digitalização da produção musical (com a substituição das gravações analógicas) permitiu o aumento da espessura da divisão social e territorial do trabalho nas cidades, englobando um conjunto dessas pequenas atividades. Uma das conclusões a que chegamos, nas diferentes cidades brasileiras, é que há um modo de produzir música comum a todos os atores do circuito superior marginal.

Os equipamentos de trabalho podem mudar, numa variação de marca e modelo, um conjunto maior ou menor de funções, maior ou menor número de canais, melhor amplitude na receptividade do som, entre outros, porque dentro do mesmo sistema de técnicas existem graus de sofisticação e de preços. Mas, o sistema de objetos, conduz ao mesmo conjunto de ações nos diferentes lugares.

As situações geográficas nos indicam que a urbanização tende a conferir aos diferentes lugares uma estrutura comum, dentro de suas respectivas especificidades. As formas de agir são impregnadas por um sistema de objetos comuns e, assim, a tecnoesfera tende a cristalizar-se nas porções do território nacional. Os sistemas técnicos não são mais locais; "o subsistema técnico hegemônico tornou-se ubíquo” (Santos, 1996, p. 153). Esse novo sistema técnico universal, onipresente em todos os lugares e que se comunica com todas as técnicas do planeta, edifica o projeto da universalidade técnica, configurando a chamada "unicidade técnica" (Santos, 1996, p. 151-156).

O consumo de objetos técnicos modernos é o alicerce para apreendermos a nova face da produção musical pelos atores do circuito superior marginal, suas potencialidades e seus constrangimentos. Os equipamentos são supervalorizados nas empresas de gravação, já que conferem graus de valorização do serviço prestado.

A instrumentalização na atividade ganhou novos conteúdos a partir dos meados dos anos 1990, como exemplo tomemos os programas para operacionalizar as gravações digitais, hoje, imperiosos no cotidiano dessa presteza. Entre esses, hoje, estão o Sound Ford, o Pro Tools, o Sonar, o Midi, o Reason, o Kake Walk e o Nero, que permitem o ajuste digital das gravações como volume, equalização, afinação de voz e, do mesmo modo, autorizam a execução em meio virtual. 
A partir do uso da informática, microcomputadores, mesas de som e programas específicos nas gravações, criou-se a nova especificidade dos serviços oferecidos pelos estúdios. Além da gravação, mixagem, masterização, agora, possibilidades, como a reprodução de discos (algumas vezes "piratas"), produção de jingles e spots para agências de propaganda e, também, trilhas para filmes, exposições artísticas e teatros são realizadas.

Nesses interstícios, a produção da música ganha novos contornos, com a criação de novas atividades, antes circunscritas apenas ao circuito superior e que, no período atual, se espraiam em sua porção marginal e no circuito inferior. Os trabalhos de campo em São Paulo, Rio de Janeiro, Porto Alegre, Recife e Goiânia, revelaram muitos exemplos de uma dinâmica economia urbana produzida por atores não poderosos. $\bigcirc$ meio construído é uma variável central, pois autoriza o uso, em soluções criativas, de formas de trabalho mais diversas dentro da música.

O estúdio Groovy, em Goiânia, já fora entrevistado em 2006. Fica no bairro residencial de Setor Bueno e funciona na garagem da casa em que moram os proprietários. É bastante comum, em pequenos e médios estúdios de gravação, que pessoas morem no mesmo local em que trabalham. A localização desse estúdio na cidade e a fachada do lugar não evidenciam o serviço ali prestado. A fiscalização não é um problema. Como um dado geral à atividade os estúdios de gravação e ensaio têm sua clientela baseados no "boca a boca". Pouco se faz de propaganda e quando o fazem, geralmente, são folhetos em lojas de instrumentos musicais ou contatos em listas telefônicas. Os contatos obtidos via internet são da tele listas.

Em Porto Alegre, em julho de 2010, entrevistamos dez estúdios de gravação. A maioria deles eram também as residências dos proprietários das atividades. Essas empresas, estúdios de gravação, não dependem de uma economia de aglomeração para manterem-se ativos no mercado da música. Como frisamos, a propaganda acontece melhor pela troca de informação pessoal dentro de um mercado com muitos interlocutores. A solidariedade orgânica é, mais uma vez, um meio de existência material para diversos atores.

As firmas de gravação e estúdios musicais tendem a se sustentar em pontos dispersos em diferentes porções da cidade, em um esquema de parceria e concorrência simultaneamente. A interdependência entre esses atores designa uma rede de contatos que tende a diminuir o peso da variável localização e fortalecer laços de cooperação e interdependência.

Nota-se, através desse pequeno conjunto de dados empíricos, que micro e pequenas empresas ligadas à produção, comercialização e difusão musical podem coexistir com a produção hegemônica da música.

\section{Considerações finais}

Os atores hegemônicos, ou seja, aqueles que detêm as variáveis do período e têm capacidade de macro-organizar o território nacional, são sobretudo os grupos Sony Corporation e Universal.

Esses agentes encontraram novos meios de controlar a produção e garantir o lucro. Por isso, são hegemônicos, pois, mesmo diante de uma reestruturação, mantêm-se em pé, controlando as variáveis da modernização. Produzem modos de pensar, nomeiam discursos e hábitos na sociedade que moldam a demanda por serviços e produtos. 
A música, dialeticamente, será, portanto, tomada num par: como instrumento de alienação (mercadoria) e de libertação (arte), sem contudo criar-se um dualismo. Ela é ambas as coisas, em maior ou menor grau.

Na ponta modernizadora, há um forte incremento de investimentos na música digital na última década. A telefonia celular, como vimos, converteu-se num dispositivo portátil de música, já que os downloads para os telefones celulares disseminaram-se mundialmente. De acordo com a International Federation of Phonographic Industry (IFPI), foram licenciadas, em 2010, 13 milhões de faixas pelas gravadoras globais para serviços digitais; 400 novos serviços via internet foram disponibilizados; 4,6 bilhões de dólares foi o valor negociado em músicas digitais no mundo.

As gravadoras globais declaram ter $29 \%$ de suas receitas em vendas pela web e, entre 2004 e 2010, segundo a IFPI, aumentou 1.000\% a receita bruta no mercado digital da música. Em entrevista na gravadora católica Paulinas, de porte médio, com sede em São Paulo, verificamos a queda na venda de discos físicos. As grandes gravadoras são, especialmente, as que perdem uma fatia do mercado, pois, em Goiânia e Porto Alegre, ao falar com músicos independentes, constatamos que, para os micro e pequenos atores, não há diferença com a difusão dos seus materiais pela internet. Ao contrário: a internet torna mais poroso o canal de comunicação entre o artista e seu público.

consumo de semoventes musicais e a banalização da informática no Brasil potencializaram a demanda por música e sua presença no cotidiano urbano. Acreditamos que a combinação entre o aumento da oferta de crédito para pessoas físicas, a banalização de tecnologias de produção, a distribuição e o consumo musical (a participação igualmente importante de microcomputadores, notebooks e tablets com acesso à rede na rotina doméstica de famílias) e, por fim, o aumento da capacidade de compra de algumas parcelas de população oxigenaram a combustão para a abertura no mercado da música de micro e pequenos agentes.

aumento da demanda tende a gerar mais trabalho, mais postos indiretos correlacionados ao circuito espacial produtivo da música, suscitando mais manifestações da cultura e expressões regionais e locais correlacionadas, bem como o crescimento do mercado entre o conjunto mais amplo de agentes.

A solidariedade orgânica é a tônica na organização de micro e pequenas firmas, a partir da interdependência de funções, contatos e, algumas vezes, por relações de proximidade - contiguidade territorial -, ainda que não estabeleçam economias de aglomeração. Por exemplo, os contatos pessoais entre os estúdios de gravação e as casas de show, bem como a propaganda de estúdios em parceria com grupos musicais que veiculam em seus encartes os telefones dos prestadores de serviços de gravação e também o contato com gráficas, geralmente nas redondezas de cada firma de gravação.

Todavia, é certo que o lugar abriga a todos, e a resistência se faz na contiguidade. Resta-nos encontrar e atualizar a crítica, sob as lentes de manifestações que são culturais mas também econômicas, sociais e políticas, colaborando em edificações mais afinadas com a realidade. Essa é nossa modesta tentativa. 


\section{Referências}

BARENBOIM, D. A música desperta o tempo. São Paulo: Martins Fontes, 2009.

BERNARDES, A. A nova divisão territorial do trabalho brasileira e a produção de informações na cidade de São Paulo (as empresas de consultoria). In: SANTOS, M.; SILVEIRA, M.

L. O Brasil: território e sociedade no início do século XXI. Rio de Janeiro: Record, 2001. p. 413-432.

BULL, M. Sound Moves: iPod culture and urban experience. Nova York: Routledge, 2007.

Sounding out the city: personal stereos and the management of everyday life. Oxford: Berg, 2000.

CANCLINI, N. G. Culturas híbridas: estratégias para entrar e sair da modernidade. São Paulo: EDUSP, 2008a.

Consumidores e cidadãos: conflitos multiculturais da globalização. Trad. Maurício Santana Dias. 7. ed. Rio de Janeiro: Editora UFRJ, 2008b.

CREUZ, V. Compassos territoriais: os circuitos da economia urbana na música em São Paulo, Rio de Janeiro, Goiânia, Recife e Porto Alegre. Dissertação (Mestrado em Geografia Humana) - Faculdade de Filosofia, Letras e Ciências Humanas, Universidade de São Paulo, São Paulo, 2012.

O direito à voz no território: circuitos da economia urbana e a produção musical nas cidades de São Paulo, Porto Alegre, Rio de Janeiro e Goiânia. Monografia (Graduação em Geografia) - Faculdade de Filosofia, Letras e Ciências Humanas, Universidade de São Paulo, São Paulo, 2008.

ELLUL, J. A técnica e o desafio do século. Trad. Roland Corbisier. Rio de Janeiro : Paz e Terra, 1968.

ETZIONI, A. Organizações modernas. Trad. Miriam L. Moreira Leite. São Paulo: Pioneira, 1967.

GOLDMANN, L. A criação cultural na sociedade moderna. São Paulo: Difusão Europeia do Livro, 1972.

GOTTMAN, J. La politique des états et leur géographie. Paris: Armand Colin, 1952. p. 160-225.

HABERMAS, J. Teoria de la acción comunicativa I: racionalidad de la acción y racionalización social. Madri: Taurus, 1988.

HARVEY, D. $\bigcirc$ trabalho, o capital e o conflito de classes em torno do ambiente construído nas sociedades capitalistas avançadas. Espaço e Debates, n. 6, p. 7-35, 1982.

LATOUR, B. Jamais fomos modernos: ensaio de antropologia simétrica. Trad. Carlos Irineu da Costa. 2. ed. Rio de Janeiro: Editora 34, 2000[1994].

LIPOVETSKY, G. A era do vazio. Trad. Therezinha Monteiro Deustch. Barueri: Manole, 2005.

MAFFESOLI, M. A república dos bons sentimentos. Iluminas: São Paulo, 2008.

RAIS. Relação Anual de Informações Sociais. Ministério do Trabalho. Brasilia, 2009. Disponível em: <http://portal.mte.gov.br/rais/>. Acesso em: 4 ago. 2014. 
RIBEIRO, A. C. T. Tecnologias da informação e comunicação, saúde e vida metropolitana. Revista Interface - Comunicação, Saúde, Educação, v. 2, n. 2, 1997.

SANTOS, M. Economia espacial - críticas e alternativas. São Paulo: Edusp, 2003[1979].

O espaço dividido - os dois circuitos da economia urbana dos países subdesenvolvidos. São Paulo: Edusp, 2002[1979].

Por uma outra globalização: do pensamento único à consciência universal. Rio de Janeiro: Record, 2000.

Técnica, espaço, tempo: globalização e meio técnico-científico- informacional. 4. ed. São Paulo: Hucitec, 1998[1994].

A natureza do espaço: técnica e tempo, razão e emoção. São Paulo: Hucitec, 1996.

. Por uma economia política da cidade: o caso de São Paulo. São Paulo: Hucitec/Educ, 1994.

. O espaço do cidadão. 4. ed. São Paulo: Nobel, 1992[1987].

. "Sociedade e espaço: a formação social como teoria e como método". Boletim Paulista de Geografia, São Paulo, n. 54, p. 81-100, jun. 1977.

SEBRAE. Serviço Brasileiro de Apoio às Micro e Pequenas Empresas. Cadeia produtiva da música. Rio de Janeiro, 2005.

SENNETT, R. A corrosão do caráter. Trad. Marcos Santarrita. 11. ed. Rio de Janeiro/São Paulo: Record, 2006a.

A cultura do novo capitalismo. Trad. Clóvis Marques. Rio de Janeiro: Record, $2006 \mathrm{~b}$.

SILVEIRA, M. L. Metrópoles do Terceiro Mundo: da história ao método, do método à história. In: SILVA, C. A.; CAMPOS, A. (Orgs.). Metrópoles em mutação: dinâmicas territoriais, poder e vida coletiva. Rio de Janeiro: Revan, 2008. p. 17-35.

. Los confines de la racionalidad: el espacio geográfico contemporáneo. In: ENCUENTRO DE GEÓGRAFOS DE AMÉRICA LATINA, 11., mar. 2007, Bogotá. Anais..., Bogotá, 2007.

. Por que há tantas desigualdades sociais no Brasil. In: ALBUQUERQUE, E. S. Que país é esse? São Paulo: Globo, 2006.

. Uma situação geográfica: do método à metodologia. Território, São Paulo, ano IV, n. 6, jan./jun. 1999.

SIMONDON, G. Du mode d'existence des objets techniques. Paris : Albier, 1989[1958].

SORRE, M. A noção de gênero de vida e sua evolução. In: MEGALE, J. F. (Org.). Max Sorre: geografia. Rio de Janeiro: Ática, 1984.

TOZI, F. Rigidez normativa e flexibilidade tropical : investigando os objetos técnicos no período da globalização. Tese (Doutorado em Geografia Humana) - Faculdade de Filosofia, Letras e Ciências Humanas, Universidade de São Paulo, São Paulo, 2012. 